\title{
The Asian opportunity
}

\author{
As rapidly developing Asian countries become major players in materials research, they have \\ the perfect opportunity to use new technologies to build a greener energy infrastructure.
}

The National Science Foundation (NSF) report of May 2007 "The Future of U.S. Chemistry Research: Benchmarks and Challenges" makes for interesting reading ${ }^{1}$. The report focuses on the current position of chemistry research in the US in comparison with the rest of the world and finds that, although still a world leader in many respects, it is facing severe challenges that mean US chemists will have to work hard to defend this position in future.

The NSF report identifies a number of countries that will be major competitors in the next ten years. Challenges are expected from Europe, but not surprisingly the primary source of concern for the NSF over the next decade is the rapid growth and investment in research in Asia; particularly serious challenges are expected in the fields of materials chemistry and nanoscience.

The month after the NSF report appeared, a study from the Netherlands Environmental Assessment Agency ${ }^{2}$ announced that China's carbon dioxide emissions overtook those from the US in 2006. This has come years earlier than expected - a fact attributed to a surge in cement production in the country, which requires massive energy input, and the general huge demand for energy generated from coal in one of the largest and most rapidly expanding economies in the world. Although in 2006 the overall level of emissions from China was higher at 6,200 million tonnes of $\mathrm{CO}_{2}$ compared with the US at 5,800 million tons, emissions per head in China were still only one quarter of that in the US.

The increase in emissions is obviously a concern, but China and other rapidly developing Asian countries now have an unparalleled opportunity as the soonto-be leaders in materials chemistry: to demonstrate to the rest of the world how economic growth can be based on revolutionary, cleaner technologies. These

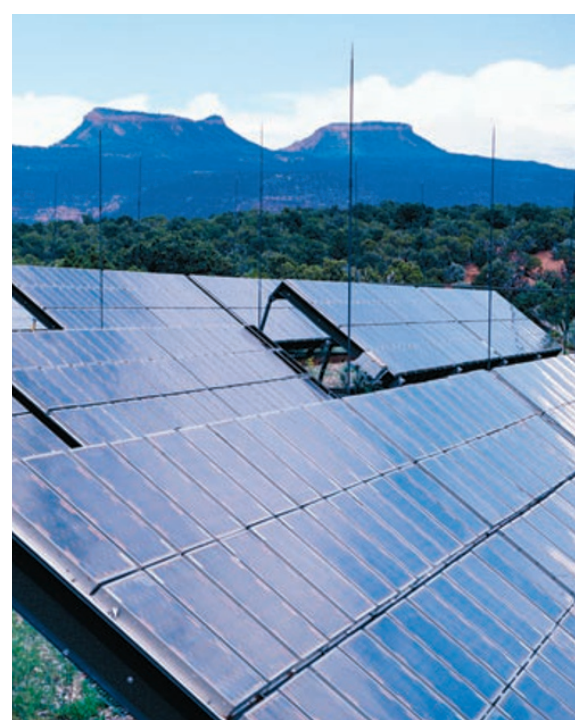

Materials for energy could mean a green future for Asia.

countries have all shown tremendous foresight with massive investment over the past few years in science and technology research - nanotechnology funding in China and South Korea reached US $\$ 250$ million and US\$205 million respectively in 2005, which compares well to the US's US\$1,606 million investment in the same year, and easily outstrips the UK's US\$160 million (ref. 3). With this investment in place, they stand in a prime position to build their energy infrastructure around the very novel technologies that their researchers are investigating.

Whether this is a fair expectation is something that many would question. In his interview with Nature Materials on page 544 of this issue ${ }^{4}$, C. N. R. Rao - chairman of the Science Advisory Council to the Indian prime minister - makes the point that as India has mostly only polluted the world with coal fires and cooking stoves until now, to expect it to take a major role in cutting emissions while it is in the process of its own industrial revolution is unfair. Indeed, some Asian countries are already pursuing more traditional alternatives to fossil fuels - Japan produces $29 \%$ of its energy via nuclear generation and South Korea 45\%. Although this is good for cutting $\mathrm{CO}_{2}$ emissions, nuclear energy has its problems too, not least its waste products, and with advances in materials for energy in particular, Asian countries have the choice of using their growing expertise in new technologies to forge ahead in the implementation of new, sustainable energy tools.

Clearly, materials chemistry in Asia is becoming a force to be reckoned with, and in this issue we offer some insights into its development. In particular, a glimpse into the Indian government priorities are provided by C. N. R. $\mathrm{Rao}^{4}$, and a commentary from Taeghwan Hyeon (page 541) illustrates the Korean strategy for rapid growth in chemistry ${ }^{5}$, particularly given their relatively late start after the Korean War in the 1950s. What is clear from both these reflections on Asian chemistry is that Asian states recognize the importance and opportunities in key areas such as materials for energy and nanoscience - both areas that the NSF report recognized as particularly competetive. It remains to be seen whether the investment and academic success that Asia is currently enjoying can be converted into usable tools for a cleaner future.

\footnotetext{
References

1. National Science Foundation. The Future of U.S. Chemistry Research: Benchmarks and Challenges (National Academies Press, Washington, 2006).

2. Netherlands Environmental Assessment Agency report; available via $<$ http://tinyurl.com/25mn8e $>$

3. National Materials Advisory Board. A Matter of Size: Triennial Review of the National Nanotechnology Initiative (National Academies Press, Washington, 2006).

4. Interview. Nature Mater. 6, 544-545 (2006)

5. Hyeon, T. Nature Mater. 6, 541-543 (2006).
} 